\title{
Genetic analysis of soybean resistance to Fusarium solani f.sp. glycines
}

\author{
Vanoli Fronza ${ }^{1}$, Natal Antonio Vello ${ }^{2,4}$ and Luis Eduardo Aranha Camargo 3,4 \\ ${ }^{1}$ Empresa de Pesquisa Agropecuária de Minas Gerais, Centro Tecnológico do Triângulo \\ e Alto Paranaíba, Uberaba, MG, Brazil. \\ ${ }^{2}$ Universidade de São Paulo, Escola Superior de Agricultura "Luiz de Queiroz", \\ Departamento de Genética, Piracicaba, SP, Brazil. \\ ${ }^{3}$ Universidade de São Paulo, Escola Superior de Agricultura "Luiz de Queiroz", \\ Departamento de Entomologia, Fitopatologia e Zoologia Agrícola, Piracicaba, SP, Brazil. \\ ${ }^{4}$ CNPq fellowship.
}

\begin{abstract}
In order to study the genetic control of soybean resistance to sudden death syndrome (SDS), a $5 \times 5$ diallel with the $F_{2}$ generation, without the reciprocals, was carried out in a greenhouse. The following parents were used: Forrest, MG/BR-46 (Conquista), IAC-4, FT-Cristalina, and FT-Estrela. The first two cultivars are more resistant to SDS than IAC-4, which is considered to be moderately resistant to SDS, and the last two cultivars are highly susceptible. The fungus was inoculated with three colonized sorghum grains placed at the bottom of the holes with two soybean seeds. Single plants were evaluated between 14 and 37 days after emergency based on foliar severity symptoms (1-5) of SDS. The disease incidence and a disease index were also calculated for each plot (clay pots with five plants each). The analysis for severity and disease index was performed only with the data of the $37^{\text {th }}$ day after emergence. Additive and dominant genetic effects were detected by Jinks-Hayman's analysis, but the dominant genetic effects were higher. The genetic parameters estimated indicated that the average degree of dominance showed the presence of overdominance; at least three loci or genic blocks that exhibited dominance were responsible for the genetic control of SDS resistance; the estimates of narrow-sense heritabilities were moderate (0.48 to 0.62$)$, but in the broad-sense they were higher (0.90 to 0.95), thus reinforcing the presence of dominance effects; and the resistance to SDS was controlled mostly by dominant alleles. Five microsatellite markers (Satt163, Satt309, Satt354, Satt371 and Satt570), reported as linked to five QRLs of the SDS, were used to genotype the parents and showed the possibility of occurrence of multiallelism in those loci, but this evidence did not invalidate the fitting of the data to the Jinks-Hayman's model.
\end{abstract}

Key words: Glycine max, resistance, sudden death syndrome-SDS, diallel crosses, Jinks-Hayman, molecular markers SSR.

Received: January 27, 2003; Accepted: February 19, 2004.

\section{Introduction}

The red rot of soybean roots (PVR in Brazil), also known as sudden death syndrome (SDS), is caused by the Fusarium solani f.sp. glycines fungus. This disease has resulted in increasing yield losses to Brazilian soybean farmers since the beginning of the last decade.

Up until this time, no chemical control or cultural method has been effective nor any cultivar immune to the disease. So, the use of more resistant cultivars is the best hope for SDS control or plant cohabitation with the fungus.

Send correspondence to Vanoli Fronza. Empresa de Pesquisa Agropecuária de Minas Gerais, Centro Tecnológico do Triângulo e Alto Paranaíba, Caixa Postal 351, 38001-970 Uberaba, MG, Brazil. E-mail: vanoli@epamig.br.
Few reports were found in the literature on the study of genetic control of soybean resistance to SDS with traditional genetic techniques and all the studies showed just one biparental cross (Stephens et al., 1993; Heavner et al., 1996; Ringler and Nickell, 1996). In one of the first studies on the inheritance of soybean resistance to SDS, with $\mathrm{F}_{2}$ and $F_{2: 3}$ segregating populations of the Ripley and Spencer reciprocal crosses in a greenhouse, it was found that the ability of Ripley to resist foliar disease symptoms was conditioned by a single dominant nuclear gene called Rfs (Stephens et al., 1993). Subsequently, in other studies, the resistance to SDS foliar symptoms in Ripley, complete and conditioned by only one dominant gene, was reaffirmed (Heavner et al., 1996; Ringler and Nickell, 1996). However, complete monogenic inheritance was observed only 
in the cultivar Ripley. So, it is possible that Ripley has a different mechanism of resistance.

Several studies with molecular markers showed that the resistance in the field is partial, polygenic and quantitative (Chang et al., 1996; Hnetkovsky et al., 1996; Njiti et al., 1998; Iqbal et al., 2001; Njiti et al., 2002). Initially, four QRLs (quantitative resistance loci) associated to the resistance to SDS were found (Chang et al., 1996; Hnetkovsky et al., 1996). In a more recent study, six QRLs responsible for SDS resistance were reported (Iqbal et al., 2001). Five of them were associated to the microsatellite molecular markers Satt214, Satt309, Satt570, all of them on linkage group (LG) G, Satt371 (LG C2) and Satt354 (LG I), and another one was associated to the RAPD marker OE02 1000 (LG G). Jointly, these QRLs explained about $91 \%$ of the total variation in SDS disease incidence of RILs (recombinant inbred lines) from the Forrest $x$ Essex cross, and they showed only the presence of additive genic action. In another study with molecular markers (RFLP, RAPD, microsatellite and AFLP), in RILs of the Pyramid x Douglas cross, Njiti et al. (2002) reported three QRLs, which jointly explained about $60 \%$ of the total variation in SDS incidence. Of these markers, one was located on LG G (Satt163), near Satt309 and Satt038, another on LG C2 (Satt307), and another on LG N (Satt080), near Satt387, which also showed a strong association to SDS QRL. According to Triwitayakorn et al. (2002), there are at least seven genes underlying resistance to SDS. They also reported that three genes on LG G (Rfs1, Rfs2 and Rfs6) were sequenced, and the next genes they will sequence are the genes on LG C2 and I, respectively, Rfs4 and Rfs5. However, in all of these studies with molecular markers, only RILs were used. No information was supplied on the presence of dominant genetic effects or whether dominant or recessive alleles predominate in the genetic control of SDS resistance.

Among the biometric methods used for genetic analysis, undoubtedly, the study of diallel crosses is the one that supplies the most information to plant breeders for conducting a breeding program with artificial hybridization. Therefore, the Jinks-Hayman method (Jinks and Hayman, 1953; Hayman, 1954a, b; Jinks, 1954) was considered powerful enough for genic action analysis, due to the degree of detailing of the analysis that makes it much more informative than the other methods (Toledo and Kiihl, 1982). Thus, this method seems sufficiently adjusted for self-pollinated crops like soybeans. With some adaptation, the JinksHayman method can also be used in the $\mathrm{F}_{2}$ generation (Hayman, 1958; Singh and Singh, 1984a), when there is a large number of seeds from each cross, making the evaluation possible for a larger number of plants in one or more environments. However, the use of this methodology requires the making of some assumptions (Hayman, 1954a, 1958), which in practice are not always totally taken care of. However, if molecular markers linked to the studied genes are used, it is possible to make more inferences on these assumptions and also to compare certain results.

In the present study, the Jinks-Hayman diallel analysis was used to investigate the inheritance of soybean resistance to SDS in order to provide information for future soybean breeding programs and to detail the use of this methodology with the $\mathrm{F}_{2}$ generation. The use of some molecular markers reported as linked to resistance genes of the SDS is also discussed.

\section{Materials and Methods}

The $\mathrm{F}_{2}$ generation of a $5 \times 5$-diallel, without the reciprocals, was used in the study. The following parents: Forrest, MG/BR-46 (Conquista), IAC-4, FT-Cristalina and FT-Estrela were used. The first two parents are more resistant to SDS than IAC-4, considered moderately resistant, and the two last are highly susceptible.

The experiment was carried out in a greenhouse, in the Department of Genetics/ESALQ/USP, in PiracicabaSP. The sowing date was July 31, 2002, and a completely randomized design, with 10 replications for each parent and 30 replications for each $\mathrm{F}_{2}$ population was used.

The isolate of $F$. solani f.sp. glycines (SDS-5) was obtained at the Embrapa Soja (Londrina-PR). It was kept in tubes $(20 \times 200 \mathrm{~mm})$ or Petri plates by successive transference in PDA medium $(250 \mathrm{~g} / \mathrm{L}$ of potato: $12 \mathrm{~g} / \mathrm{L}$ of dextrosol: $18 \mathrm{~g} / \mathrm{L}$ of common or bacteriological agar). To increase the fungus, $100 \mathrm{~cm}^{3}$ of red-sorghum grains were soaked overnight in distilled water in a $500 \mathrm{~mL}$ Erlenmeyer flask, drained, and autoclaved on two consecutive days for $20 \mathrm{~min}$ at $120^{\circ} \mathrm{C}$. Each of the flasks containing sterilized sorghum grains was inoculated by transferring 15 (5-mm-diameter) mycelial plugs from the PDA colonies. Ten milliliters of sterile distilled water were added to each flask for better dispersion of the spores and mycelium and to maintain humidity in the sorghum grains. Cultures on sorghum grains were incubated in the dark for 24 days at temperatures ranging from $22{ }^{\circ} \mathrm{C}$ to $\pm 2{ }^{\circ} \mathrm{C}$. To allow for a uniform growth of the fungus around the sorghum grains and to maintain the grains untied, the flasks were agitated periodically.

The fungus was inoculated by the colonized sorghum grain technique (Hartman et al., 1997), and was placed at the bottom of each hole when sowing (Balardin and Rubin, 1999). Five holes, $4 \mathrm{~cm}$ deep, were made in each ceramic pot with three liters of unsterilized soil, which came from an uncultivated area. Each pot had five plants. Three sorghum grains were placed in each hole, in direct contact with the soybean seeds (two/hole). Thinning took place soon after the emergency, leaving one plant per hole. Soon thereafter, inoculating oil containing Bradyrhizobium japonicum, was mixed in the irrigation water and applied with a watering can. 
Five days after the emergency, 5-g of ammonium sulfate was applied to each pot, followed by irrigation. The soil humidity was maintained, at a minimum of $-4 \mathrm{~cm}$ of $\mathrm{Hg}$ (about $-0.05 \mathrm{~atm}$ ), and measured with a tensiometer placed $8 \mathrm{~cm}$ deep.

Thirteen days after the emergency another inoculation was done by pressing two colonized sorghum grains 1 $\mathrm{cm}$ deep, next to the taproot of each plant, with the aid of a glass stick.

Fifty plants of each parent and 150 plants of each $\mathrm{F}_{2}$ population were evaluated individually, with intervals of three or four days, between the $14^{\text {th }}$ and $37^{\text {th }}$ days after the emergency. Only the data from the last evaluation were used for the analyses. The severity of the SDS foliar symptoms was evaluated based on the leaflet with the most intense symptoms and on the general appearance of the plant. The severity of SDS was rated 1 to 5, as used by Hartman et al. (1997), and modified for the following: $\mathbf{1}=$ no visible foliar symptoms; 2 = slight symptom development, with chlorosis in mosaic, and deformation or wrinkling of the leaflets; $\mathbf{3}=$ moderate symptom development, with interveinal chlorosis and necrosis on the border of the leaflets; $\mathbf{4}$ = heavy symptom development, with chlorosis and interveinal necrosis (no more than $50 \%$ of foliar area affected by necrosis); $\mathbf{5}=$ severe symptom development, with chlorosis and interveinal necrosis and/or plant death or severe restriction in the development of the plants (51\% to $100 \%$ of foliar area affected by necrosis). The average severity of the disease (DS) and the percentage of disease incidence (DI) in each plot (ceramic pot) were calculated and a disease index [(DS x DI)/5] was obtained, according to Njiti et al. (1998).

The analyses of variance according to the design used was followed by the analyses of variance of diallel tables, according to the procedures of Ramalho et al. (1993), derived from complete diallel tables (Hayman, 1954b), and adapted to half diallel tables by Jones (1965). In these analyses the pooled error of the initial ANOVA was used, and it was divided by the harmonic average (18) of replications of parents and $\mathrm{F}_{2}$ populations.

These analyses of variance of diallel tables were followed by the diallel analyses of the data obtained with the $\mathrm{F}_{2}$ generation, according to the theoretical bases developed for the $F_{1}$ generation (Hayman, 1954a), adapted for the $F_{2}$ generation, using half diallel tables with " $n$ " parents (Singh and Singh, 1984a). From these tables the following variances and covariances were estimated for each trait: $V_{p}, V_{r}$, $\overline{\mathrm{V}}_{\mathrm{r}}, \mathrm{V}_{\mathrm{r}}, \mathrm{W}_{\mathrm{r}}$, and $\overline{\mathrm{W}}_{\mathrm{r}}$. The mean of the parents $\left(\mathrm{ML}_{0}\right)$ and $\mathrm{F}_{2}$ populations $\left(\mathrm{ML}_{2}\right)$ were also calculated.

The goodness of fit of the additive-dominant model was performed based on the linear regression of the values of $\hat{W}_{r}$ on $\hat{V}_{r}$, in two ways: 1) to verify if the angular coefficient of the straight line (b) was equal to unit $\left(\mathrm{H}_{0}: \mathrm{b}=1\right.$ vs. $\mathrm{H}_{1}: \mathrm{b} \neq 1$ ) (Cruz and Regazzi, 1997); and 2) to verify if the angular coefficient of the straight line ( $\left.b^{\prime}\right)$ was zero $\left(\mathrm{H}_{0}\right.$ : $\left.b^{\prime}=0 v s . \mathrm{H}_{1}: b^{\prime} \neq 0\right)$, after the rotation of $45^{\circ}$ on the axis of the graph (Hayman, 1954a).

The following genetic components were estimated: $\mathrm{D}, \mathrm{H}_{1}, \mathrm{H}_{2}$ and $\mathrm{F}$, after the fitting of the data to the genetic model of Jinks-Hayman was verified. For the estimate of these components of genetic variation the following equations, adapted to half diallel tables, were used with the data from the $\mathrm{F}_{2}$ generation, according to Singh and Singh (1984a):

$$
\begin{aligned}
& \hat{\mathrm{D}}=\hat{\mathrm{V}}_{\mathrm{p}}-\mathrm{E}_{0} \\
& \hat{\mathrm{H}}_{1}=4 \hat{\mathrm{V}}_{\mathrm{p}}+16 \overline{\hat{\mathrm{V}}}_{\mathrm{r}}-16 \overline{\hat{\mathrm{W}}}_{\mathrm{r}}-\frac{4\left[\mathrm{nE}_{0}+4(\mathrm{n}-1) \mathrm{E}_{2}\right]}{\mathrm{n}} \\
& \hat{\mathrm{H}}_{2}=16 \overline{\hat{\mathrm{V}}}_{\mathrm{r}}-16 \hat{\mathrm{V}}_{\mathrm{r}}-\frac{16\left[(\mathrm{n}-1) \mathrm{E}_{0}+\left(\mathrm{n}^{2}-2 \mathrm{n}+1\right) \mathrm{E}_{2}\right]}{\mathrm{n}^{2}} \\
& \hat{\mathrm{F}}=4 \hat{\mathrm{V}}_{\mathrm{p}}-8 \overline{\hat{\mathrm{W}}}_{\mathrm{r}}-\frac{4(\mathrm{n}-2) \mathrm{E}_{0}}{\mathrm{n}}
\end{aligned}
$$

The specific errors of the initial ANOVA, showed for $\mathrm{E}_{0}$ (mean square of the error of parents divided by 10) and $E_{2}$ (mean square of the error of $F_{2}$ populations divided by 30 ), were used due to the fact that the parents had 10 replications and the $\mathrm{F}_{2}$ populations had 30 replications each.

The standard error of each genetic component was estimated based on the following variance (Hayman, 1954a): $\mathrm{s}^{2}=\hat{\mathrm{V}} \operatorname{ar}\left(\hat{\mathrm{W}}_{\mathrm{r}}-\hat{\mathrm{V}}_{\mathrm{r}}\right) / 2$. This variance was then multiplied by the specific coefficients for each genetic component, for the $\mathrm{F}_{2}$ generation with the complete diallel table according to Hayman (1958). Each coefficient was corrected for half diallel tables, and then the square root was extracted to obtain the standard error of each component. The correction of each coefficient for half diallel tables was done in percentages based on the observed difference between the specific coefficients of each component, for a $5 \times 5$ diallel, supplied to the $F_{1}$ generation with complete diallel table data according to Hayman (1954a), and supplied to the $F_{1}$ generation with half diallel table data, according to Ferreira (1985). The correction factor obtained for each coefficient was then multiplied by the coefficient supplied to the $F_{2}$ generation (Hayman, 1958). The significance of each component was then tested for the $t$ test, with " $n-2$ " degrees of freedom, in which the value of " $\mathrm{t}$ " was obtained by the division of the estimate of each component by its respective standard error (Singh and Chaudhary, 1979).

From the estimates of the genetic components, the following genetic parameters were estimated, and their interpretations are related exclusively to the group of parents used in the present study (fixed model): 1) add $=\sqrt{\hat{\mathrm{H}}_{1} / \hat{\mathrm{D}}}$;
2) $\frac{\hat{\mathrm{K}}_{\mathrm{D}}}{\hat{\mathrm{K}}_{\mathrm{R}}}=\frac{\sqrt{4 \hat{\mathrm{DH}}_{1}}+\hat{\mathrm{F}}}{\sqrt{4 \hat{\mathrm{D}}_{1}}-\hat{\mathrm{F}}}$;
3) $\overline{\mu \mathrm{v}}=\frac{\hat{\mathrm{H}}_{2}}{4 \hat{\mathrm{H}}_{1}} ;$ 
$\hat{\mathrm{N}}=\frac{16\left(\mathrm{ML}_{2}-\mathrm{ML}_{0}\right)^{2}}{\hat{\mathrm{H}}_{2}}$ (estimated from the equation of Jinks, 1954, and adapted for the $\mathrm{F}_{2}$ generation by Santos,

$$
\begin{aligned}
& \text { 1984); 5) } \hat{\mathrm{h}}_{\mathrm{ns}}^{2}=\frac{\frac{\hat{\mathrm{D}}}{2}+\frac{\hat{\mathrm{H}}_{1}}{2}-\frac{\hat{\mathrm{H}}_{2}}{2}-\frac{\hat{\mathrm{F}}}{2}}{\frac{\hat{\mathrm{D}}}{2}+\frac{\hat{\mathrm{H}}_{1}}{2}-\frac{\hat{\mathrm{H}}_{2}}{4}-\frac{\hat{\mathrm{F}}}{2}+\frac{\hat{\mathrm{E}}}{\mathrm{r}}} \\
& \hat{\mathrm{h}}_{\mathrm{bs}}^{2}=\frac{\frac{\hat{\mathrm{D}}}{2}+\frac{\hat{\mathrm{H}}_{1}}{2}-\frac{\hat{\mathrm{H}}_{2}}{4}-\frac{\hat{\mathrm{F}}}{2}}{\frac{\hat{\mathrm{D}}}{2}+\frac{\hat{\mathrm{H}}_{1}}{2}-\frac{\hat{\mathrm{H}}_{2}}{4}-\frac{\hat{\mathrm{F}}}{2}+\frac{\hat{\mathrm{E}}}{\mathrm{r}}} .
\end{aligned}
$$

The heritability in the narrow and broad-sense was calculated in level of plot means, according to Mather and Jinks (1982). The value of $\hat{E} / \mathrm{r}$ was obtained from the division of the mean square of the general error of the initial ANOVA by the harmonic average (18) of replications of parents and $\mathrm{F}_{2}$ populations.

The following genetic information was also obtained (Cruz and Regazzi, 1997): 1) coefficient of correlation between favorable alleles and dominance (r); and, 2) concentration of dominant and recessive alleles in the parents $\left(\hat{\mathrm{W}}_{\mathrm{r}}+\hat{\mathrm{V}}_{\mathrm{r}}\right)$.

The diallel analyses were performed by electronic spreadsheets in the Excel program (Microsoft $\AA$ Excel 97).

Five microsatellite molecular markers (Satt163, Satt309, Satt354, Satt371 and Satt570), reported as linked to five QRLs of the SDS (Iqbal et al., 2001; Njiti et al., 2002), were also used to genotype the parents. This part of the study was done at the Laboratory of Molecular Genetics of the Department of Entomology, Phytopathology and Agricultural Zoology of the ESALQ/USP. The extractions of DNA and PCRs (polimerase chain reactions) were done according to Schuster (1999), with some modifications. Electrophoresis for the microsatellite markers was performed in sequencing gel containing $6 \%$ polyacrylamide, $7 \mathrm{M}$ urea and $1 \mathrm{X}$ TBE (Tris-Borate $90 \mathrm{mM}$ and EDTA $2 \mathrm{mM}$ ), at $60 \mathrm{~W}$ for three and half hours. The gel was then silver stained. For more details, see Fronza (2003).

\section{Results and Discussion}

The results of the goodness of fit of the JinksHayman's additive-dominant genetic model are showed in Table 1. It was observed that, in all cases, for the test and for the F test, the coefficient of linear regression (b) was not significantly different from the unit, indicating the fitting of the data to the model and absence of epistasis in the control of SDS resistance in all the traits evaluated. However, all the values of $r^{2}$ were below $90 \%$, and all standard errors were higher than 0.1 . Thus, the influence of the environment probably helped to mask the relationship of $\hat{\mathrm{W}}_{\mathrm{r}}$ on $\hat{\mathrm{V}}_{\mathrm{r}}$, making the assumptions of the model only marginally valid for some traits. According to Jinks and Hayman (1953), the reduction of the heterozygosity in the $\mathrm{F}_{2}$ generation makes it more difficult to detect anomalies in the data for the method, based on dominant genetic effects. Thus, the most probable causes of distortions could be the presence of multiallelism and the correlated distribution of genes among the parents. The occurrence of epistasis is not quite probable. This is because in studies with molecular markers (Njiti et al., 1998; Iqbal et al., 2001; Njiti et al., 2002), the presence of epistasis between the markers linked to QRLs, which underlined the resistance to SDS, was not detected. The presence of multiallelism was shown by the use of the microsatellite markers Satt163, Satt309, Satt354, Satt371 and Satt570, but there is no certainty that this multiallelism in the loci of the markers corresponds to the occurrence of multiallelism in the loci responsible for the SDS resistance. The assumption that there is an independent distribution of genes among the parents may not be true. This is due to the fact that the M-2 line, one of the parents of Estrela, is a sister line of Cristalina, and also because Cristalina could be the result of a natural crossing between UFV-1 and Davis, according to Spehar (1994). Thus, Cristalina and Conquista could have Davis as a common ancestor. According to Hayman (1954a), a probable consequence of the presence of a correlated distribution of genes among the parents is the overestimation of the average degree of dominance, discussed later.

Table 1 - Goodness of fit of Jinks-Hayman's additive-dominant model based on regression analysis of $\hat{W}_{\mathrm{r}}$ on $\hat{\mathrm{V}}_{\mathrm{r}}$.

\begin{tabular}{lcccc}
\hline & & & $\mathrm{t}$ & $\mathrm{F}=\mathrm{ct}^{2} "$ \\
Trait & $\hat{\mathrm{b}} \pm \mathrm{s}_{\mathrm{b}}$ & $\mathrm{r}^{2}(\%)$ & $\left(\mathrm{H}_{0}: \mathrm{b}=1\right)$ & $\left(\mathrm{H}_{0}: \mathrm{b}\right.$ ' $\left.=0\right)$ \\
\hline leaflet severity (LDS) & $0.74 \pm 0.20$ & $82.0^{* 1 /}$ & $-1.30^{\mathrm{ns}}$ & $0.69^{\mathrm{ns}}$ \\
leaflet disease index (LDX) & $0.43 \pm 0.23$ & $52.0^{\mathrm{ns}}$ & $-2.45^{\mathrm{ns}}$ & $1.94^{\mathrm{ns}}$ \\
plant severity (PDS) & $0.80 \pm 0.18$ & $86.7^{*}$ & $-1.08^{\mathrm{ns}}$ & $0.49^{\mathrm{ns}}$ \\
plant disease index (PDX) & $0.50 \pm 0.24$ & $59.8^{\mathrm{ns}}$ & $-2.07^{\mathrm{ns}}$ & $1.45^{\mathrm{ns}}$ \\
\hline
\end{tabular}

\footnotetext{
${ }^{1 /}$ Result of the variance analysis of the linear regression model.

* and **: significant at the $5 \%$ and $1 \%$ levels, respectively, by $\mathrm{F}$ test.

${ }^{n s}$ : not significant.
} 
Table 2 - Analysis of variance of the diallel tables for the evaluated traits.

\begin{tabular}{lrcccc}
\hline \multirow{2}{*}{ Sources of variation } & & \multicolumn{4}{c}{ Mean squares } \\
\cline { 3 - 5 } & DF & LDS & LDX & PDS & PDX \\
\hline Treatments & 14 & $0.195463^{* *}$ & $150.63^{* *}$ & $0.186379^{* *}$ & $135.38^{* *}$ \\
$\mathrm{a}$ & 4 & $0.475577^{* *}$ & $267.27^{* *}$ & $0.481969^{* *}$ & $259.11^{* *}$ \\
$\mathrm{~b}$ & 10 & $0.083417^{*}$ & $103.97^{* *}$ & $0.068143^{*}$ & $85.89^{* *}$ \\
$\mathrm{~b}_{1}$ & 1 & $0.233307^{*}$ & $382.78^{* *}$ & $0.256040^{* *}$ & $365.40^{* *}$ \\
$\mathrm{~b}_{2}$ & 4 & 0.091180 & $103.21^{* *}$ & 0.063778 & $79.04^{*}$ \\
$\mathrm{~b}_{3}$ & 5 & 0.047229 & 48.82 & 0.034055 & 35.47 \\
Pooled error & 335 & 0.041172 & 30.12 & 0.033916 & 24.83 \\
\hline
\end{tabular}

* and **: significant at the $5 \%$ and $1 \%$ levels, respectively, by $\mathrm{F}$ test.

The results of the analyses of variance of the additive and dominance genetic components are shown in Table 2. For all traits, highly significant effects were observed for the " $a$ " source of variation (additive genic effects). The " $b$ " source of variation (dominant genetic effects) also showed highly significant effects $(p<0.01)$ for the disease index (LDX and PDX) and only significant effects $(p<0.05)$ for the severity of the foliar symptoms (LDS and PDS). This indicates that the additive and dominant genetic effects contributed to the control of the SDS resistance for all traits. However, the dominant genetic effects were more intense for the disease index than for the severity of the disease.

The " $b_{1}$ " component was highly significant for all the traits, except for severity based on the leaflet with more intense symptoms (LDS) (Table 2). The significance of the " $b_{1}$ " component indicates that the dominance was predominantly in one direction (Ramalho et al., 1993). Since the average of the $\mathrm{F}_{2}$ populations was always lower than that of the average of the parents (data not shown), it was concluded that the dominance deviations occurred in the direction of an increase in the SDS resistance (Fronza, 2003).

The " $\mathrm{b}_{2}$ " component was significant for the disease index (LDX and PDX) and showed a tendency toward significance $(\mathrm{p}<0.10)$ for the severity of the foliar symptoms (LDS and PDS) of the SDS (Table 2). Thus, there was evidence that some parents had a greater ratio of dominant alleles than others. This implies in the presence of asymmetry in the distribution of favorable and unfavorable alleles among the parents (Hayman, 1954b). According to Ramalho et al. (1993) this means that there was evidence that some parents had a significantly better performance than others, when considering the average of crosses in which each one participated.

The estimates of the genetic components $\mathrm{D}, \mathrm{H}_{1}, \mathrm{H}_{2}$ and $\mathrm{F}$, and the respective standard errors are shown in Table 3. The standard errors of the genetic components were generally high and the significance of the effects of these components for each trait did not always follow the results of the variance analyses (Table 2), considered to be more accurate. The absence of significant effects of the additive genetic component $\mathrm{D}$, which was statistically equal zero (Table 3), in contrast to that observed for the "a" source of variation (Table 2), was the main discrepancy found.

In general, the additive and dominant genetic effects explained the differences between the treatments. It was also observed that the dominant genetic effects were higher for the disease index (LDX and PDX) than for the severity (LDS and PDS) of the foliar symptoms, since in the variance analyses the effect of the "b" source of variation was highly significant $(\mathrm{p}<0.01)$ only for the calculated disease index (Table 2). On the other hand, only for severity (LDS and PDS) were the estimates of D higher than the respective

Table 3 - Estimates of genetic components of variation of Jinks-Hayman's additive-dominant model with standard errors.

\begin{tabular}{lcccc}
\hline & \multicolumn{4}{c}{ Estimates \pm standard errors } \\
\cline { 2 - 5 } Traits & $\hat{\mathrm{D}}$ & $\hat{\mathrm{H}}_{1}$ & $\hat{\mathrm{H}}_{2}$ & $\hat{\mathrm{F}}$ \\
\hline LDS & $0.1380 \pm 0.0705$ & $0.6874^{*} \pm 0.1494$ & $0.5575^{* *} \pm 0.0867$ & $-0.2334 \pm 0.1755$ \\
LDX & $23.00 \pm 91.03$ & $1127.81^{*} \pm 192.85$ & $901.90^{* *} \pm 111.84$ & $-218.75 \pm 226.49$ \\
PDS & $0.1476 \pm 0.0533$ & $0.4753^{*} \pm 0.1130$ & $0.4160^{* *} \pm 0.0655$ & $-0.2523 \pm 0.1327$ \\
PDX & $27.74 \pm 72.35$ & $879.35^{*} \pm 153.28$ & $718.39^{* *} \pm 88.90$ & $-223.53 \pm 180.02$ \\
\hline
\end{tabular}

\footnotetext{
${ }^{1 /}$ The standard errors of the estimates were calculated according to Hayman (1958) and corrected to half diallel tables based on Ferreira (1985).

* and **: significant at the 5\% and $1 \%$ levels, respectively, by $t$ test, according to Singh and Chaudhary (1979).
} 
standard errors, though not significantly higher than zero (Table 3).

The estimates of the genetic component $\mathrm{F}$ were generally a little higher than the standard errors, but always negative. Thus, even if no estimate of the genetic component $\mathrm{F}$ was significantly different from zero, this frequency of negative values could be an indication of the predominance of recessive alleles in the group of parents. This is according to the level of resistance of the parents and is another indication that dominant alleles control the SDS resistance in this group of parents. The " $\mathrm{b}_{2}$ " source of variation was significant for the disease index (LDX and PDX, Table 2), and indicates differences in the ratio of dominant and recessive alleles among the parents. This also may be an indication that the parents considered to be resistant (Forrest and Conquista) show greater concentration of dominant alleles than the others.

The values obtained for the average degree of dominance (add), in general, were very high (Table 4). This demonstrated the presence of overdominance, which also was shown by the intercept point between the regression straight line and the covariance axis (Figures 1 and 2), i.e., below origin or below "AB/2", according to Singh and Singh (1984b); "A" is the point of intersection of the straight line of regression with the covariance axis and "B" is the point of intersection of the parallel straight line to the straight line of regression and tangent to the limiting parabola with the covariance axis. For the previously commented results on the analyses of variance (Table 2) and the estimates obtained for the genetic components (Table 3 ) and the graphs (Figures 1 and 2), the existence of dominance in the control of the SDS resistance in this experiment was confirmed. However, the values of the average degree of dominance seem to be overestimated (Table 4), especially for the disease index of the foliar symptoms (LDX and PDX). According to Ferreira (1988), the equations of the genetic components of the original method of JinksHayman (Jinks and Hayman, 1953; Hayman, 1954a; Jinks, 1954) led to overestimates of the values of $D$ and $H_{1}$, causing an $85 \%$ overestimation in the average degree of dominance in a 6 x 6 diallel. According to Hayman (1954a), Nassar (1965), and Ferreira (1988), the correlated distribution of the genes in the parents would be the cause of over- estimates in the average degree of dominance. However, the exclusion of Cristalina for suspicion of correlated distribution of genes with Conquista and Estrela decreased the value of the average degree of dominance by $20 \%$ only for the disease index (LDX and PDX) (Fronza, 2003). This exclusion also increased the value of the angular coefficient (b) and the " $r$ " of the model of regression for this trait, but did not improve the fitting of the severity (LDS and PDS) data to the model.

The ratio of the total number of dominant and recessive alleles in the parents $\left(\hat{\mathrm{K}}_{\mathrm{D}} / \hat{\mathrm{K}}_{\mathrm{R}}\right)$ was always lower than 1.0 (Table 4), indicating a higher frequency of recessive alleles in the parents. This result is in accordance to the trend observed for the estimates of the genetic component $\mathrm{F}$, although none of the $\mathrm{F}$ estimates was significantly different from zero (Table 3 ).

The product of the average frequencies of the positive and negative effects of the alleles in the loci where dominance occurs $(\overline{\mu v})$, indicated the presence of small asymmetry in the distribution of the positive and negative alleles in the parents (Table 4). This is in accordance to the result already shown by the significance of the " $\mathrm{b}_{2}$ " source of variation (Table 2).

The number of effective factors $(\hat{\mathrm{N}})$ varied between 2.01 and 2.95 (Table 4). The estimate was higher when the severity was based on the general appearance of the plant in the evaluation of the foliar symptoms of the SDS (PDS). The results indicated that there are at least two or three loci (or genic blocks) that show dominance and confer resistance to the manifestation of the SDS foliar symptoms. This character is probably controlled by a large number of loci because additive genic effects were also found (Table 2). In studies with molecular markers, even in field assessments, seven QRLs underlying the SDS resistance were detected (Chang et al., 1996; Hnetkovsky et al., 1996; Iqbal et al., 2001; Njiti et al., 2002; Triwitayakorn et al., 2002). In most all of these studies, Forrest was used as the resistant parent, presenting five out of seven QRLs found: linked to molecular markers Satt080, Satt163, Satt309, Satt570 and OE02 1000 . This confirms the underestimation of the number of loci that controlled the SDS resistance in the present study, where Forrest was also used. Moreover, there may have been other QRLs underlying the SDS resistance in the

Table 4 - Estimates of genetic parameters, dominance decreasing order and coefficient of correlation between the favorable alleles and dominance (r).

\begin{tabular}{|c|c|c|c|c|c|c|c|c|}
\hline \multirow[b]{2}{*}{ Traits } & \multicolumn{6}{|c|}{ Genetic parameters } & \multirow{2}{*}{$\begin{array}{c}\text { Dominance decreasing } \\
\text { order }^{1 /}\end{array}$} & \multirow[b]{2}{*}{$\mathrm{r}$} \\
\hline & add & $\hat{\mathrm{K}}_{\mathrm{D}} / \hat{\mathrm{K}}_{\mathrm{R}}$ & $\overline{\mu v}$ & $\hat{\mathrm{N}}$ & $\hat{\mathrm{h}}_{\mathrm{ns}}^{2}$ & $\hat{\mathrm{h}}_{\mathrm{bs}}^{2}$ & & \\
\hline LDS & 2.23 & 0.45 & 0.20 & 2.01 & 0.58 & 0.90 & $\mathrm{CO}, \mathrm{CR}, \mathrm{FO}, \mathrm{ES}, \mathrm{I} 4$ & 0.61 \\
\hline LDX & 7.00 & 0.19 & 0.20 & 2.04 & 0.48 & 0.95 & $\mathrm{CO}, \mathrm{CR}, \mathrm{FO}, \mathrm{ES}, \mathrm{I} 4$ & 0.65 \\
\hline PDS & 1.80 & 0.35 & 0.22 & 2.95 & 0.62 & 0.91 & $\mathrm{CO}, \mathrm{CR}, \mathrm{FO}, \mathrm{ES}, \mathrm{I} 4$ & 0.66 \\
\hline PDX & 5.63 & 0.17 & 0.20 & 2.44 & 0.51 & 0.95 & $\mathrm{CO}, \mathrm{CR}, \mathrm{FO}, \mathrm{ES}, \mathrm{I} 4$ & 0.66 \\
\hline
\end{tabular}

${ }^{1 /}$ Increasing order of $\hat{\mathrm{W}}_{\mathrm{r}}+\hat{\mathrm{V}}_{\mathrm{r}}$. CO: Conquista, CR: Cristalina, ES: Estrela, FO: Forrest, and I4: IAC-4. 

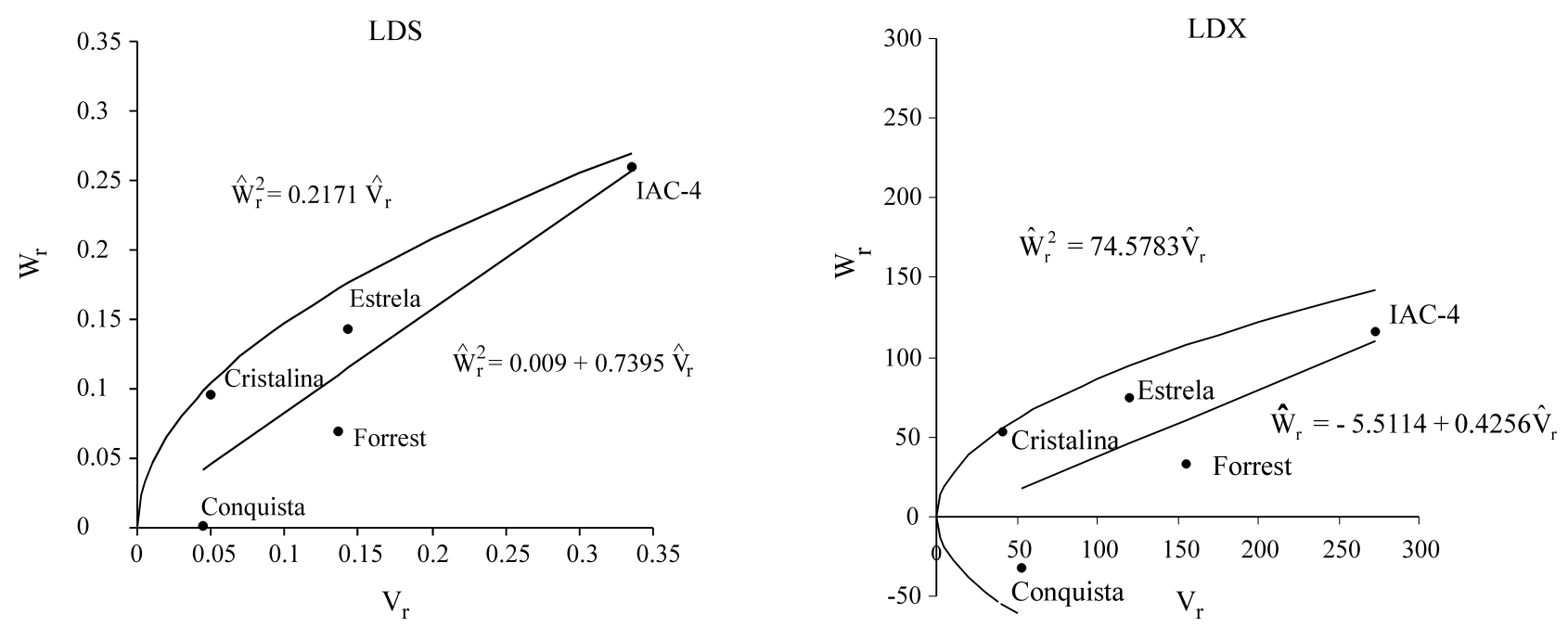

Figure 1 - Regression of $\mathrm{W}_{\mathrm{r}}$ on $\mathrm{V}_{\mathrm{r}}$ for severity (LDS) and disease index (LDX) of the SDS foliar symptoms based on the leaflet with the most intense symptoms.
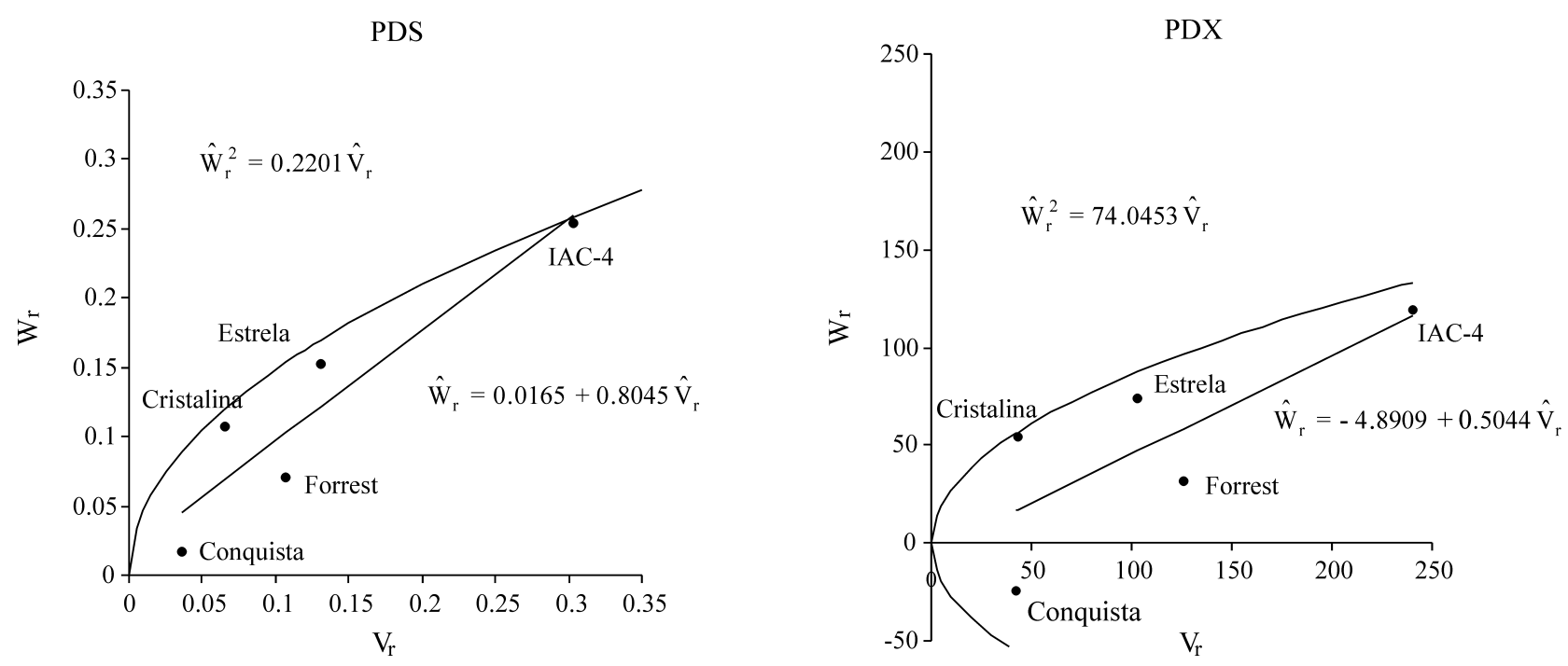

Figure 2 - Regression of $\mathrm{W}_{\mathrm{r}}$ on $\mathrm{V}_{\mathrm{r}}$ for severity (PDS) and disease index (PDX) of the SDS foliar symptoms based on the general appearance of the plant.

other parents that were included in this study. This is due to the fact that alleles of resistance can be present either in SDS-resistant or -susceptible parents, as already demonstrated (Chang et al., 1996; Hnetkovsky et al., 1996; Njiti et al., 1998; Iqbal et al., 2001; Njiti et al., 2002). In this way, by the molecular analysis, at least one more QRL, linked to the molecular marker Satt354, was present in the Conquista and Cristalina cultivars. This QRL was the same one found in the susceptible cultivar Essex, in the study by Iqbal et al. (2001), because Essex was used as a check in the present study.

The values of the narrow-sense heritability $\hat{\mathrm{h}}_{\mathrm{ns}}^{2}$ were about $10 \%$ higher when the severity of the foliar symptoms of SDS (LDS and PDS) was considered (Table 4). But the values of the broad-sense heritability $\hat{\mathrm{h}}_{\mathrm{bs}}^{2}$ were about $5 \%$ lower for the severity of the foliar symptoms of the SDS
(LDS and PDS), indicating that severity was just a little more affected by the environment than the disease index. The differences observed between the narrow and broad-sense heritabilities reflected the presence of the dominant genetic effects on the control of the SDS resistance. The high values obtained for both heritabilities were due, probably, to the large number of replications used, since these heritabilities were estimated on plot means.

The dominance order of the parents was always the same: Conquista, Cristalina, Forrest, Estrela, and IAC-4 (Table 4). The regression graphs (Figures 1 and 2) also showed that Conquista and IAC-4 have the highest and lowest concentrations of dominant alleles, respectively. However, among the other three parents, with intermediate positions in the graphs, it would be necessary to consider the distance of each one from the origin. With regard to the severity of the foliar symptoms (LDS and PDS), Cristalina 
and Forrest were relatively similar, and they showed more dominant alleles than Estrela; however, for the disease index (LDX and PDX), Estrela and Forrest were similar, and showed fewer dominant alleles than Cristalina.

The relation between the favorable alleles and dominance (r) indicated that the lower values of severity and disease index of the foliar symptoms of the SDS were correlated with the lower values of $\hat{\mathrm{W}}_{\mathrm{r}}+\hat{\mathrm{V}}_{\mathrm{r}}$ (Table 4), i.e., a higher concentration of dominant alleles. This was also shown by the position of the parents in the regression graphs (Figures 1 and 2). The values of " $r$ " were not close to 1.0, and the decreasing order of dominance and the position of the parents in the regression graphs were somewhat different from the expected. So, it may be that recessive alleles may also have contributed to the control of the manifestation of the foliar symptoms of the SDS in the group of cultivars studied.

It was concluded that the resistance of the soybean to the SDS, caused by F. solani f.sp. glycines and measured by the foliar symptoms of the disease, was inherited quantitatively and controlled mainly by dominant genetic effects. This suggests that the evaluations for the selection of more resistant genotypes to the SDS must be done at advanced generations of inbreeding. For these evaluations, only the severity of the foliar symptoms of the SDS, based on the scale (1-5) used in this study showed itself to be appropriate. The use of molecular markers linked to the QRLs of the SDS can also be of great aid in the choice of parents with different alleles of resistance, making the QRL pyramiding possible.

\section{Acknowledgements}

The authors would like to thank: FAPESP for financial support; CNPq for the fellowships granted; the researchers of the Embrapa Soja (Londrina-PR), Dr. Leones A. Almeida for sending the seeds of the cultivars used, and Dr. José Tadashi Yorinori, for the SDS-5 isolate; Janice I.H.V. Pinto, an undergraduate student from the Agronomic Engineering course at ESALQ/USP, for her help during the evaluations; and Ângela C.A. Lopes, for supplying the first version of the electronic spreadsheet used in the diallel analyses.

\section{References}

Balardin RS and Rubin SAL (1999) Reação de germoplasma de soja à Fusarium solani f.sp. glycines. Congresso Brasileiro de Soja, Londrina, PR, Brazil, p 461.

Chang SJC, Doubler TW, Kilo V, Suttner R, Klein J, Schmidt ME, Gibson PT and Lightfoot DA (1996) Two additional loci underlying durable field resistance to soybean sudden death syndrome (SDS). Crop Sci 36:1684-1688.

Cruz CD and Regazzi AJ (1997) Modelos Biométricos Aplicados ao Melhoramento Genético. 2nd edition. UFV, Viçosa, 390 pp.
Ferreira PE (1985) On Jinks-Hayman's analysis of half diallels. Braz J Genet 8:149-155.

Ferreira PE (1988) A new look at Jinks-Hayman's method for the estimation of genetical components in diallel crosses. Heredity 60:347-353.

Fronza V (2003) Genética da reação da soja a Fusarium solani f.sp. glycines. PhD Thesis, Escola Superior de Agricultura "Luiz de Queiroz", Universidade de São Paulo, Piracicaba, SP, Brazil. (http://www.teses.usp.br/teses/disponiveis/11/ 11137/tde-19052003-160041/publico/vanoli.pdf)

Hartman GL, Huang YH, Nelson RL and Noel GR (1997) Germplasm evaluation of Glycine max for resistance to Fusarium solani, the causal organism of sudden death syndrome. Plant Dis 81:515-518.

Hayman BI (1954a) The theory and analysis of diallel crosses. Genetics 39:789-809.

Hayman BI (1954b) The analysis of variance of diallel tables. Biometrics 10:235-244.

Hayman BI (1958) The theory and analysis of diallel crosses. II. Genetics 43:63-85.

Heavner DL, Nickell CD and Kolb FL (1996) Genetic analysis of the response of the soybean cultivar Asgrow A4715 to Fusarium solani. Soybean Genet Newslett 23:144-148.

Hnetkovsky N, Chang SJC, Doubler TW, Gibson PT and Lightfoot DA (1996) Genetic mapping of loci underlying field resistance to soybean sudden death syndrome (SDS). Crop Sci 36:393-400.

Iqbal MJ, Meksem K, Njiti VN, Kassem MA and Lightfoot DA (2001) Microsatellite markers identify three additional quantitative trait loci for resistance to soybean sudden-death syndrome (SDS) in Essex x Forrest RILs. Theor Appl Genet 102:187-192.

Jinks JL (1954) The analysis of continuous variation in a diallel cross of Nicotiana rustica varieties. Genetics 39:767-788.

Jinks JL and Hayman BI (1953) The analysis of diallel crosses. Maize Genet Coop News Lett 27:48-54.

Jones RM (1965) Analysis of variance of the half diallel table. Heredity $20: 117-121$.

Mather K and Jinks JL (1982) Biometrical Genetics: The Study of Continuous Variation. 3rd edition. Chapman and Hall, London, $396 \mathrm{pp}$.

Nassar RF (1965) Effect of correlated gene distribution due to sampling on the diallel analysis. Genetics 52:9-20.

Njiti VN, Doubler TW, Suttner RJ, Gray LE, Gibson PT and Lightfoot DA (1998) Resistance to soybean sudden death syndrome and root colonization by Fusarium solani f.sp. glycines in near-isogenic lines. Crop Sci 38:472-477.

Njiti VN, Meksem K, Iqbal MJ, Johnson JE, Kassem MA, Zobrist KF, Kilo VY and Lightfoot DA (2002) Common loci underlie field resistance to soybean sudden death syndrome in Forrest, Pyramid, Essex, and Douglas. Theor Appl Genet 104:294-300.

Ramalho MAP, Santos JB and Zimmermann MJO (1993) Genética quantitativa em plantas autógamas: aplicações ao melhoramento do feijoeiro. UFG, Goiânia, 271 pp.

Ringler GA and Nickell CD (1996) Genetic resistance to Fusarium solani in Pioneer Brand 9451 soybean. Soybean Genet Newslett 23:149-154.

Santos JB (1984) Controle genético de caracteres agronômicos e potencialidades de cultivares de feijão (Phaseolus vulgaris L.) para o melhoramento genético. $\mathrm{PhD}$ Thesis, Escola $\mathrm{Su}-$ 
perior de Agricultura "Luiz de Queiroz", Universidade de São Paulo, Piracicaba, SP, Brazil.

Schuster I (1999) Identificação de QTL para resistência ao nematóide de cisto da soja e capacidade de combinação de genitores. PhD Thesis, Universidade Federal de Viçosa, Viçosa, MG, Brazil.

Sing RK and Chaudhary BD (1979) Biometrical methods in quantitative genetic analysis. 2nd edition. Kalyani Publishers, New Delhi, 304 pp.

Singh M and Singh RK (1984a) Some theoretical aspects of analysis in half diallel. Biom J 26:63-68.

Singh M and Singh RK (1984b) Hayman's graphical analysis in segregating generations of a diallel cross. Biom J 26:69-74.
Spehar CR (1994) Breeding soybeans to the low latitudes of Brazilian cerrados (savannahs). Pesq Agropec Bras 29:11671180.

Stephens PA, Nickell CD and Kolb FL (1993) Genetic analysis of resistance to Fusarium solani in soybean. Crop Sci 33:929930.

Toledo JFF and Kiihl RAS (1982) Métodos de análise dialélica do modelo genético em controle das características dias para floração e número de folhas trifolioladas em soja. Pesq Agropec Bras 17:745-755.

Triwitayakorn KT, Jamai A, Schulz J, Iqbal J, Meksem K, Town C and Lightfoot DA (2002) Genomic approaches to molecular breeding of resistance to soybean sudden death syndrome and cyst nematode in elite cultivars. Embrapa Soja. Anais do II Congresso Brasileiro de Soja, Foz do Iguaçu, PR, Brazil, pp 70-71.

Associate Editor: Marcio de Castro Silva Filho 